\title{
Getzel M. Cohen \& Martha Sharp Joukowsky (eds), Breaking Ground: Pioneering Women Archaeologists
} The University of Michigan Press, Ann Arbor, 2004, first paperback edition 2006, $571 \mathrm{p}$.

\section{Renée Champion}

\section{(2) OpenEdition}

Journals

Édition électronique

URL : https://journals.openedition.org/clio/8992

DOI : 10.4000/clio.8992

ISSN : 1777-5299

Éditeur

Belin

Édition imprimée

Date de publication : 15 décembre 2008

Pagination : 275-307

ISSN : 1252-7017

\section{Référence électronique}

Renée Champion, « Getzel M. Cohen \& Martha Sharp Joukowsky (eds), Breaking Ground: Pioneering Women Archaeologists », Clio. Histoire, femmes et sociétés [En ligne], 28 | 2008, mis en ligne le 16 décembre 2008, consulté le 22 avril 2022. URL : http://journals.openedition.org/clio/8992 ; DOI : https://doi.org/10.4000/clio.8992

Ce document a été généré automatiquement le 22 avril 2022.

Tous droits réservés 


\section{Getzel M. Cohen \& Martha Sharp Joukowsky (eds), Breaking Ground: Pioneering Women Archaeologists}

The University of Michigan Press, Ann Arbor, 2004, first paperback edition 2006, $571 \mathrm{p}$.

\section{Renée Champion}

1 Le titre anglais de ce volume très épais (Breaking Ground) joue sur les deux sens de l'expression, « frayer un chemin »/« creuser la terre », soulignant le rôle novateur des premières femmes archéologues, pionnières pour leur sexe et dans la discipline scientifique, dès ses débuts à la fin du xix ${ }^{\mathrm{e}}$ siècle. L'ouvrage revient ainsi à la préhistoire de la participation des femmes à l'archéologie qui a déjà été évoquée dans des volumes tels que Women in Archaeology (éd. C. Claassen, Pennsylvania Univ. Press, 1994) et Excavating Women: A History of Women in European Archaeology (éd. M. Diaz-Andreu et M. Sorensen, Routledge, 1998).

2 Breaking Ground est composé de douze biographies, organisées de façon chronologique à partir de la date de naissance de ces femmes archéologues, américaines, anglaises et canadiennes, ou française pour l'une d'entre elles, la première dans la chronologie (voir le chapitre d'Eve Gran-Aymerich sur Jane Dieulafoy, célèbre pour les fouilles entreprises avec son mari à Suse, dans la Perse des années 1880, et dont les trésors sont aujourd'hui visibles au Louvre). Elles ont surtout effectué (participé ou dirigé) des fouilles dans la région de la Méditerranée (Italie, Grèce, Crète) et du Proche et MoyenOrient. Si certaines sont connues, à l'instar de Dieulafoy ou de Gertrude Bell, la plupart restent des noms méconnus, sauf pour des spécialistes averti(e)s. Ainsi, l'un des buts de l'ouvrage est de rendre visibles des femmes archéologues qui ont été systématiquement occultées dans l'histoire de l'archéologie et les biographies collectives, et de souligner l'importance de leurs contributions, souvent novatrices, à la discipline. Un dossier iconographique et des cartes géographiques accompagnent le texte.

3 L'introduction importante de Margaret Cool Root (33 pages) situe ces biographies (« un groupe représentatif et non pas exhaustif des femmes exemplaires ») dans un contexte 
socio-historique plus large, en distinguant deux générations de femmes archéologues : celle nées vers le milieu du XIXe siècle et jusqu'en 1890 ; celle nées entre 1890 et 1910. Le premier groupe aurait émergé des idéologies victoriennes concernant le rôle de la femme, au moment où l'archéologie s'est établie au sein des institutions. La deuxième génération s'est confrontée à d'autres difficultés, l'archéologie étant devenue une possibilité de carrière: notamment la discrimination au sein des institutions et la misogynie des directeurs des sites des fouilles.

Les quatorze auteur(e)s viennent de disciplines différentes, archéologie, histoire et histoire de l'art, ce qui contribue à la richesse de l'ouvrage. Source documentaire, les chapitres sont copieusement annotés, avec souvent recours, quand c'est possible, aux archives personnelles des archéologues, mettant en lumière de nouveaux matériaux. A travers les histoires individuelles, les parcours intellectuels, les voyages, les expériences sur le terrain, les difficultés à trouver des financements (provenant parfois de fortunes familiales), leur vie de famille (seulement trois femmes sur douze étaient mariées, deux avec enfants), leurs publications, la reconnaissance par les pairs (pouvant se traduire par l'obtention de postes professionnels, la constitution des collections dans des musées, la transmission de savoir), nous avons une meilleure idée des obstacles spécifiques aux femmes archéologues ainsi que de leurs contributions aux pratiques et techniques, à l'enseignement et à l'histoire de l'archéologie.

On découvre aussi certains paradoxes (par exemple, Dorothy Garrod, l'un des premiers archéologues à travailler en Palestine, a occupé une chaire à Cambridge, avant que l'université prestigieuse n'accepte des étudiantes au même titre que les étudiants en 1948) ; certaines complexités (les prises de positions antiféministes de Bell); ainsi que certains aléas (deux archéologues n'ont pas publié sur leurs excavations principales), conflits et controverses. On découvre aussi d'autres intérêts et activités de ces femmes (Esther Van Deman, spécialiste des aqueducs et des techniques de construction romaines, jouit d'un certain renom aujourd'hui comme photographe). Plusieurs ont participé aux efforts de guerre dans leur pays d'origine ou se sont engagées auprès des pays qui les accueillaient. Souvent aussi, elles se sont occupées du bien-être de leurs ouvriers et de leurs familles.

6 Un thème qui émerge en filigrane à travers les biographies est l'extraordinaire réseau féminin dans lequel la plupart de ces femmes travaillaient (collègues, co-équipières, mentors, sponsors, professeures). Des nombreuses autres femmes archéologues sont mentionnées dans les textes et les notes. A ce titre, il est à signaler qu'un site-web à Brown University prolonge le travail amorcé ici, en ajoutant d'autres biographies de femmes archéologues : http://www.brown.edu/Research/Breaking_Ground/.

7 Si les chapitres de Breaking Ground sont inégaux, selon les sources disponibles et les regards des biographes (textes parfois trop détaillés pour des non-spécialistes), la lecture de cet ouvrage sera très utile pour mieux comprendre l'histoire des femmes archéologues mais aussi l'histoire des sciences à la lumière des rapports de genre. 